\title{
Indicações de plantas medicinais realizadas por raizeiros para tratamento de feridas
}

Maria Willianne Alves do Nascimento ${ }^{1}$, Regina Célia Sales Santos Veríssimo ${ }^{2}$, Maria Lysete de Assis Bastos ${ }^{3}$, Thaís Honório Lins Bernardo ${ }^{4}$

\footnotetext{
${ }^{1}$ Enfermeira. Maceió, AL, Brasil. E-mail: mariawillianne@hotmail.com.

${ }^{2}$ Enfermeira, Doutora em Biotecnologia. Professora Adjunta da Universidade Federal de Alagoas (UFAL). Maceió, AL, Brasil. E-mail: salesregina@hotmail.com.

${ }^{3}$ Enfermeira, Doutora em Química e

Biotecnologia. Professora Adjunta da UFAL.

Maceió, AL, Brasil. E-mail:

lysetebastos@gmail.com.

${ }^{4}$ Enfermeira, Doutora em Biotecnologia. Professora Adjunta da UFAL. Maceió, AL, Brasil. E-mail:

thais.bernardo@esenfar.ufal.br.
}

Recebido: 16/07/2014.

Aceito: 01/10/2015.

Publicado: 31/03/2016.

Como citar esse artigo:

Nascimento MWA, Veríssimo RCSS, Bastos MLA, Bernardo THL. Indicações de plantas medicinais realizadas por raizeiros para tratamento de feridas. Rev. Eletr. Enf. [Internet]. 2016 [acesso em:

____18:e1152. Disponível em: http://dx.doi.org/10.5216/ree.v18.31143.

\begin{abstract}
RESUMO
Objetivou-se identificar plantas medicinais indicadas por comerciantes raizeiros no tratamento de feridas, em feiras livres. Pesquisa descritiva realizada em uma capital do nordeste brasileiro, por meio de entrevistas. Resultados indicam que a comercialização das plantas pelos raizeiros de ambos os sexos, com idade predominante entre 37 e 52 anos, dos quais 69,3\% aprenderam sobre a função com familiares. Foram citadas 48 espécies vegetais para tratamento de feridas, entre elas Barbatimão e Aroeira referidas por todos participantes. Das plantas Sambacaitá, Urtiga Aberta, Uchi Amarelo, Corona, Xiquexique, Sena e Pindaíba não foram encontradas propriedades que comprovam sua indicação para uso em feridas. A casca do caule foi a parte da planta mais citada $(96,15 \%), 81,03 \%$ dos participantes informaram que as plantas devem ser mantidas secas para conservação. Estudos que esclareçam atividades biológicas e efeitos colaterais das plantas medicinais são necessários, além de capacitações para raizeiros sobre indicações, preparo, armazenamento/conservação, prazo de validade. Descritores: Plantas Medicinais; Enfermagem em Saúde Comunitária; Cicatrização de Feridas; Comercialização.
\end{abstract}

\section{INTRODUÇÃO}

Desde épocas remotas, as sociedades humanas acumulam informações e experiências sobre o ambiente que as cerca, para com ele interagir e prover suas necessidades de sobrevivência ${ }^{(1)}$. Dentre tantas práticas difundidas pela cultura popular, as plantas sempre tiveram fundamental importância, por inúmeras 
razões, sendo salientadas as suas potencialidades terapêuticas aplicadas ao longo das gerações ${ }^{(1)}$.

O uso indiscriminado e informal das plantas medicinais torna o enfermeiro uma peça-chave na melhoria dos tratamentos, visto que pelo tipo de atividade profissional e proximidade com as pessoas que cuida, possui rico vínculo com a comunidade e é capaz de oferecer maior acessibilidade sobre esses tratamentos em saúde ${ }^{(2)}$. Nesse sentido, torna-se importante a valorização da cultura popular pelos profissionais de saúde, através da busca do conhecimento adquirido pelos comerciantes raizeiros e o entendimento da realidade em que a equipe está inserida.

Com o desenvolvimento da ciência e da biotecnologia as plantas medicinais estão tendo seu valor terapêutico pesquisado e ratificado cientificamente e vem crescendo sua utilização recomendada por profissionais de saúde, com a criação de políticas e programas no propósito de ampliar as opções terapêuticas aos usuários, e garantir o acesso a plantas medicinais, a fitoterápicos e a serviços relacionados à fitoterapia, com segurança, eficácia e qualidade, na perspectiva da integralidade da atenção à saúde para "promover e reconhecer as práticas populares e tradicionais de uso de plantas medicinais, fitoterápicos e remédios caseiros" ${ }^{\prime 3)}$.

Nesse contexto, o papel do enfermeiro em orientar e assistir a população no que diz respeito ao uso dessas plantas é deficiente mesmo nos dias atuais. Tal fato se deve, principalmente, à falta de conhecimento científico por parte dos profissionais, quer seja por deficiência no sistema acadêmico, quer seja por falta de interesse na área ${ }^{(2)}$.

O raizeiro, profissional que manipula e comercializa plantas medicinais, assume papel na preservação e divulgação desse conhecimento. São pessoas reconhecidas pela comunidade, têm espaço garantido nas ruas. Estes preparam líquidos denominados "garrafadas", comercializam, orientam como usá-las e preparálas para curar as mais diversas doenças, apresentando ou não, um conhecimento específico sobre o verdadeiro uso das plantas/raízes que comercializam, seus efeitos adversos e interações medicamentosas.

Considerando a importância de realizar buscas que reafirmem os benefícios e comprovações de eficácia das plantas medicinais, o objetivo desse estudo foi realizar o levantamento e a identificação das plantas medicinais indicadas pelos comerciantes raizeiros bem como a sua aplicação para o tratamento de feridas.

\section{MÉTODOS}

Pesquisa descritiva de abordagem quantitativa, realizado em feiras livres de uma capital do nordeste brasileiro. A utilização de feiras livre se deu pelo fato de ser o local onde as plantas medicinais são comercializadas e por ser o raizeiro, a pessoa que indica qual planta deve ser utilizada para determinado fim, assim como, dosagem, forma de utilização e armazenamento.

Os critérios de inclusão adotados consideraram os raizeiros que comercializavam, em feiras livres, plantas ou raízes utilizadas para o tratamento de feridas. Desta forma, foram abordados uma população de 35 comerciantes raizeiros de 19 feiras livres da cidade de Maceió, dos quais 26 aceitaram participar deste 
estudo constituindo a amostra.

Para a realização das entrevistas foi utilizado um roteiro semiestruturado contendo duas partes, com dados de identificação, como sexo, idade, profissão e local que reside; e 12 perguntas objetivas sobre a indicação das plantas medicinais para tratamento de feridas. Tais perguntas abordaram: quais as plantas ou raízes que são indicadas para o tratamento de feridas; como utilizar, tempo de tratamento, armazenamento e validade; em quais tipos de feridas; como o mesmo obteve conhecimento sobre tais plantas ou raízes; se há consumidores e se os mesmos retornam para novas compras e/ou informam sobre o seu uso e eficácia.

A coleta de dados do estudo foi realizada no período de dezembro de 2013 a maio de 2014, o recrutamento se deu por meio de convite durante visitas as feiras livres pela pesquisadora principal. A coleta de dados ocorreu nas ruas das feiras livres ou dentro de estabelecimentos comerciais pertencentes aos raizeiros, também localizados nas feiras livres. Ocorreu por meio de entrevista que tiveram duração média de 30 minutos e foram registradas em formulários estruturados desenvolvidos pelos pesquisadores.

A análise dos dados foi realizada com estatística descritiva utilizando-se frequência e intervalo de confiança.

A referida pesquisa foi avaliada e aprovada pelo Comitê de Ética e Pesquisa - CEP da Universidade Federal de Alagoas sob o no 16809313.5.0000.5013, no qual consta no Parecer no 460.762. Aos participantes foram apresentados os objetivos do estudo e solicitado que assinassem o Termo de Consentimento Livre e Esclarecido, contendo o direito ao sigilo, ao livre acesso aos dados e a liberdade de retirar-se da pesquisa a qualquer momento.

\section{RESULTADOS}

Dos 26 raizeiros participantes da pesquisa, 50\% são do sexo masculino. Sobre a profissão exercida a maioria dos entrevistados $(76,9 \%)$ alegaram ser apenas comerciantes enquanto que outras profissões foram citadas como exercidas em concomitância com a atividade de comercialização (doméstica, auxiliar topográfico, vigilante, artesão, agricultor e pedagogo) com 3,85\% cada. Quanto à idade dos raizeiros houve predominância entre 37 a 52 anos (46,2\%), seguidos de pessoas com idade entre 21 e 36 anos (30,8\%).

Quando questionados sobre com quem aprenderam sobre a utilização dessas plantas medicinais 69,3\% (18/26) afirmaram que aprenderam com familiares, dentre eles pai, mãe, tio, irmã, prima, avós. Ainda $19,2 \%(5 / 26)$ aprenderam com amigos e $11,5 \%$ (3/26) dos entrevistados por meio dos estudos.

Ao serem perguntados sobre quais as plantas medicinais são indicadas para o tratamento de feridas, foram citadas 48 plantas, das quais cinco apresentaram destaque: Barbatimão e Aroeira foram citadas por todos os entrevistados, o Cajueiro, o Sambacaitá e Angico tiveram maior destaque na frequência de indicação (Tabela 1). 
Tabela 1: Caracterização e frequência de indicação para o uso de das plantas medicinais pelos raizeiros para pacientes portadores de feridas identificadas no estudo. Maceió, AL, Brasil, 2014.

\begin{tabular}{|c|c|c|c|c|c|}
\hline $\begin{array}{l}\text { Planta medicinal e referencia de } \\
\text { indicação de efeito cicatrizante }\end{array}$ & Nome científico da espécie & Propriedade cicatrizante & Parte da planta utilizada & Frequência (\%) & Intervalo de Confiança (IC) \\
\hline Barbatimão $^{(4-5)}$ & Stryphnodendron adstringens & Sim & Casca de caule / raiz & $26(100,00)$ & $0,86-1$ \\
\hline Aroeira $^{(5-14)}$ & Myracrodruon urundeuva & Sim & Casca de caule / folha/ raiz & $26(100,00)$ & $0,86-1$ \\
\hline Cajueiro $^{(5)}$ & Anacardium occidentale $L$ & Sim & Casca de caule & $19(73,15)$ & $0,53-0,86$ \\
\hline Sambacaitá & Hyptis pectinata & - & Casca de caule / folha & $20(77,00)$ & $0,57-0,89$ \\
\hline Angico $^{(5)}$ & Anadenanthera colubrina & Sim & Casca de caule & $10(38,50)$ & $0,22-0,57$ \\
\hline Quixaba $^{(5)}$ & Bumelia sartorum & Sim & Casca de caule & $04(15,40)$ & $0,05-0,34$ \\
\hline Garrida ${ }^{(6)}$ & Turner aulmifolia & Sim & Raiz & $03(11,55)$ & $0,03-0,29$ \\
\hline Jatobá(7) & Hymenaea courbaril L. & Outras propriedades & Casca de caule & $03(11,55)$ & $0,03-0,29$ \\
\hline Urtiga aberta & Urtica urens $L$. & - & Raiz & $01(03,85)$ & $0,00-0,20$ \\
\hline Copaíba ${ }^{(8)}$ & Copaífera langsdorffii & Sim & Caule & $01(03,85)$ & $0,00-0,20$ \\
\hline Uchi amarelo & Endopleura uchi & - & Casca de caule & $02(07,70)$ & $0,01-0,25$ \\
\hline Quebra pedra ${ }^{(9)}$ & Phyllanthus niruri L. & Sim & Folha/ raíz & $02(07,70)$ & $0,01-0,25$ \\
\hline Unha de gato $^{(10)}$ & Dolichandra unguis-cat & Outras propriedades & Folha/ raiz & $02(07,70)$ & $0,01-0,25$ \\
\hline Malva branca $a^{(11)}$ & Waltheria americana & Sim & Casca de caule / folha/ raiz & $01(03,85)$ & $0,00-0,20$ \\
\hline Consolida da Amazônia & * & - & Folha & $01(03,85)$ & $0,00-0,20$ \\
\hline Alfavaca $^{(10)}$ & Ocimumbasilicum L & Sim & Casca de caule / folha/ raiz & $02(07,70)$ & $0,01-0,25$ \\
\hline Catuaba $^{(5)}$ & Anemopaegma arvense & Não & Raiz & $01(03,85)$ & $0,00-0,20$ \\
\hline Gergelin $^{(10)}$ & Sesamum indicum & Outras propriedades & Semente & $01(03,85)$ & $0,00-0,20$ \\
\hline Corona & Mascagnia pubiflora & - & Folha & $01(03,85)$ & $0,00-0,20$ \\
\hline Jucá(5-11) & Caesalpinia ferrea & Sim & Casca de caule & $02(07,70)$ & $0,01-0,25$ \\
\hline Urtiga branca $^{(5)}$ & Copaífera langsdorffii & Outras propriedades & Raiz & $02(07,70)$ & $0,01-0,25$ \\
\hline Jurema preta $^{(10)}$ & Mimosa tenuiflora & Sim & Casca de caule & $01(03,85)$ & $0,00-0,20$ \\
\hline Xiquexique & Pilosocereus polygonus & - & Raiz & $01(06,70)$ & $0,00-0,20$ \\
\hline Amora ${ }^{(12)}$ & Morus nigra L & Sim & Folha/ casca de caule & $01(03,85)$ & $0,00-0,20$ \\
\hline Teiú $^{(5)}$ & Casearia sylvestris & Sim & Casca de caule / Folha & $01(03,85)$ & $0,00-0,20$ \\
\hline Arroz chocho & * & - & Caule & $01(03,85)$ & $0,00-0,20$ \\
\hline Gapé & * & - & Caule & $01(03,85)$ & $0,00-0,20$ \\
\hline Pindaíba & Xylopia emarginata & - & Semente & $01(03,85)$ & $0,00-0,20$ \\
\hline Espinheira Santa $^{(13)}$ & Maytenus officinalis & Não & Folha & $04(15,40)$ & $0,05-0,34$ \\
\hline Alecrim ${ }^{(14)}$ & Rosmarinus officinalis $L$. & Não & Folha & $01(03,85)$ & $0,00-0,20$ \\
\hline $\operatorname{Pita}^{(12)}$ & Agave americana & Sim & Casca de caule & $02(07,70)$ & $0,01-0,25$ \\
\hline
\end{tabular}




\begin{tabular}{|c|c|c|c|c|c|}
\hline $\begin{array}{l}\text { Planta medicinal e referencia de } \\
\text { indicação de efeito cicatrizante }\end{array}$ & Nome científico da espécie & Propriedade cicatrizante & Parte da planta utilizada & Frequência (\%) & Intervalo de Confiança (IC) \\
\hline Boldo $^{(9)}$ & Plectranthus barbatus & Não & Folha & $01(03,85)$ & $0,00-0,20$ \\
\hline Anis Estrelado ${ }^{(6)}$ & Illicium verum & Não & Semente & $01(03,85)$ & $0,00-0,20$ \\
\hline Açafrão ${ }^{(10)}$ & Curcuma longa & Não & Semente & $01(03,85)$ & $0,00-0,20$ \\
\hline Canela $^{(9)}$ & Cinnamomum zeylanicum & Não & Casca de caule & $01(03,85)$ & $0,00-0,20$ \\
\hline Senna & Senna occidentalis $L$. & - & Folha & $01(03,85)$ & $0,00-0,20$ \\
\hline Erva doce ${ }^{(9)}$ & Pimpinella anisumn $L$. & Não & Semente & $01(03,85)$ & $0,00-0,20$ \\
\hline Babosa ${ }^{(15)}$ & Alo ebarbadensis & Sim & Folha & $01(03,85)$ & $0,00-0,20$ \\
\hline Cana do Brejo ${ }^{(10)}$ & Costus spicatus & Não & Folha & $01(03,85)$ & $0,00-0,20$ \\
\hline Cedro $^{(15)}$ & Luehea grandiflora & Não & Casca de caule & $01(03,85)$ & $0,00-0,20$ \\
\hline Ameixa ${ }^{(15)}$ & Ximenia americana $L$ & Não & Casca de caule & $01(03,85)$ & $0,00-0,20$ \\
\hline Pau D'arco ${ }^{(15)}$ & Tabebuia empetiginosa & Outras propriedades & Casca de caule & $01(03,85)$ & $0,00-0,20$ \\
\hline Bom-nome $e^{(14)}$ & Maytenusrigida Mart & Sim & Casca de caule & $01(03,85)$ & $0,00-0,20$ \\
\hline Pega Pinto ${ }^{(15)}$ & Boerhavia hirsuta Wiild. & Outras propriedades & Raiz & $01(03,85)$ & $0,00-0,20$ \\
\hline
\end{tabular}


Quanto à parte da planta que é utilizada, foram citadas: casca de caule, folha, caule, raiz, semente, óleo do caule, seiva, dos quais a parte mais citada foram as cascas do caule em $96,15 \%$ das entrevistas realizadas, a folha foi citada em $61,5 \%$ das entrevistas, raiz em $23,07 \%$ das entrevistas, semente em $15,4 \%$ das entrevistas e óleo do caule e seiva citada em 3,85\% das entrevistas cada.

As plantas citadas pelos raizeiros que são listadas na Relação Nacional de Plantas Medicinais de Interesse ao SUS (RENISUS) foram: Barbatimão, Urtiga branca, Babosa, Açafrão, Cana-do-brejo, Camomila e Teiú.

Em relação aos tipos de feridas para os quais as citadas plantas devem ser utilizadas, 53,85\% (14/26) afirmaram que a utilidade das plantas/raízes serve para todos os tipos de feridas, sendo elas internas ou externas. Para $42,3 \%(11 / 26)$ dos participantes do estudo as plantas servem apenas para feridas de pele (externas). Apenas um entrevistado (3,85\%) afirmou que a utilização das plantas medicinais é apenas para feridas internas.

Em relação ao retorno dos consumidores $38,45 \%$ (10/26) dos entrevistados afirmaram que os consumidores procuram as mesmas plantas, enquanto $15,35 \%(4 / 26)$ dos raizeiros afirmaram que os consumidores retornam para a aquisição somente de outras plantas. Alguns consumidores ainda retornam para adquirir, além da mesma, outras plantas de acordo com 46,2\% (12/26) entrevistados.

Sobre a satisfação do usuário quanto ao sucesso do tratamento dessas plantas, $92,3 \%$ dos entrevistados (24/26), afirmaram que seus clientes informaram sobre o uso e satisfação com as plantas adquiridas, enquanto $7,7 \%$ (2/26) informaram que os clientes obtiveram êxito parcial.

Quanto à validade, 69,3\% (18/26) apontaram que o prazo é indeterminado e 19,25\% (5/26) que o prazo se estende enquanto as plantas estiverem secas, $7,7 \%(2 / 26)$ dos raizeiros afirmaram que as plantas duram de um a dois anos e 3,85\% (1/26) afirmou que estas duram em média seis meses.

Sobre o armazenamento das plantas, $42,35 \%(11 / 26)$ dos entrevistados afirmaram que as plantas devem ser armazenadas em sacos secos, 26,85 \% (7/26) referiram sobre o armazenamento como exposto e sem umidade, 15,4 \% (4/26) descreveram apenas o armazenamento em local seco, 7,7\% (2/26) afirmaram que as plantas devem ser armazenadas protegidas do sol e outros $7,7 \%(2 / 26)$ afirmaram que devem ser armazenados enquanto estiverem secas independente do local de armazenamento.

Em relação ao tempo de utilização após o preparo, 38,5\% (10/26) dos participantes responderam que o consumo deve ser imediato. Contudo, 34,6\% (9/10) responderam que esse tempo não deve ultrapassar 24 horas sendo portanto a preparação diária. Outros 19,2 \% (5/26) acreditavam que o prazo de uso após preparam era de dois a quatro dias. Referiram como tempo de utilização indeterminado 3,85 \% (1/26) e outros $3,85 \%$ (1/26) não soube informar.

Sobre o tempo de terapia para a cicatrização das feridas com o uso das plantas medicinais preparadas, $38,5 \%(10 / 26)$ dos raizeiros afirmaram que a terapia deve durar o tempo que for necessário. Para 26,9\% (7/26) dos entrevistados a terapia dura de três a 10 dias em média. Outros 19,2 \% dos entrevistados afirmaram que 15 dias seria o tempo necessário para uso das preparações nas feridas. De um a dois meses 
foi o prazo de uso de preparos das plantas medicinais para $7,7 \%(2 / 26)$ dos entrevistados. Ainda $3,85 \%$ (1/26) referiram que este prazo depende da alimentação que o portador de ferida adota durante o uso dos preparados de plantas medicinais.

Por fim, observa-se no estudo que quando indagados sobre a interação com outra planta durante a terapia 50\% (13/26) dos entrevistados afirmaram que não existe nenhuma outra planta que interfira no tratamento. Enquanto que outros 34,6\% (9/26) dos entrevistados afirmaram que sim, e que por este motivo recomendam um tratamento por vez. Enquanto, 7,7 \% (2/26) refere que existe interação, mas que outras plantas medicinais podem complementar o tratamento. Ainda, outros $7,7 \%(2 / 26)$ referiram não ter conhecimento sobre possíveis interações entre as plantas medicinais.

Das 48 plantas citadas pelos raizeiros, deste estudo, 35,4 \% (17/48) plantas comprovam suas propriedades cicatrizantes na literatura (Tabela 1) de acordo com suas respectivas referências. Nove plantas (9/48) comprovam outras propriedades que podem contribuir para a cicatrização de feridas, tais como propriedades anti-inflamatória, antibactericida, antifúngica entre outras (Tabela 1).

Apenas sete das plantas citadas constam no RENISUS com seus respectivos nomes científicos. Vale ressaltar que em quatro das plantas citadas (Consolida da Amazônia, Gaicó, Arroz chocho e Gapé) não foram encontrados seus nomes científicos, nem propriedades a elas determinadas.

\section{DISCUSSÃO}

O presente estudo realizou levantamento das plantas medicinais que são comercializadas e indicadas por comerciantes raizeiros nas feiras livres da cidade de Maceió-AL para o tratamento de feridas.

O comércio de plantas medicinais na área estudada é uma atividade exercida tanto por homens quanto por mulheres, visto que foi constatado um percentual de $50 \%$ para ambos os sexos. Em estudo semelhante foi observado em São Luiz/MA, Belém/PA e Teresina/PI, em que houve a predominância masculina na comercialização informal de plantas medicinais ${ }^{(16)}$ Em Passo Fundo/RS também constatou-se tal fato ${ }^{(16)}$.

Quase metade dos raizeiros $(46,15 \%)$ apresentou faixa etária entre 37 e 52 anos, seguidos de pessoas com idade entre 21 e 36 anos (30,76\%). Estudo ${ }^{(17)}$ obteve resultado semelhante, 46,2\% dos raizeiros com idade entre 21 e 51 anos, ambos estudos com faixas etárias dos raizeiros entrevistados em idade produtiva.

Em relação à fonte dos conhecimentos que os entrevistados possuíam acerca dos usos e indicações das plantas medicinais 69,3\% afirmaram tê-los recebido no âmbito familiar. Fontes como mídia escrita (livros e jornais) e eletrônica (televisão, internet, entre outros) não foram mencionadas por nenhum dos comerciantes. A relevância do ambiente familiar na transmissão de conhecimentos tradicionais também foi ressaltada em estudo realizado em Maceió/AL, em que registraram que em 56,54\% dos casos a transmissão do conhecimento etnobotânico se deu por meio de informações fornecidas por pais ou avós ${ }^{(16)}$. No mesmo estudo, a participação da mídia impressa (livros, revistas) foi de apenas $6,5 \%{ }^{(16)}$. Na cidade de Vilhena/RO a predominância da transmissão oral de tais conhecimentos no âmbito familiar também foi constatado ${ }^{(16)}$.

Apesar da grande penetração das mídias impressa e eletrônica junto à população, as mesmas ainda 
não possuem influência significativa sobre a transmissão do conhecimento etnobotânico entre os comerciantes de plantas medicinais estudados, o que evidencia o caráter fortemente tradicional da atividade $^{(17)}$.

Dentre as plantas medicinais comercializadas pelos raizeiros aquelas indicadas para o tratamento de feridas foram 48, dentre essas, Barbatimão, Aroeira, Cajueiro, Sambacaitá e Angico foram as cinco espécies frequentemente citadas.

Em estudo sobre plantas medicinais com ação anti-inflamatória comercializadas em Arapiraca no mesmo estado deste estudo (Alagoas), verificou-se que os raizeiros entrevistados comercializam plantas há muitos anos, e destacou que as plantas mais vendidas são barbatimão, aroeira, cajueiro, angico, quixabeira e mijo de ovelha, coincidindo com quatro das mais frequentes neste estudo ${ }^{(18)}$.

Estudo semelhante foi desenvolvido nas feiras livres de Campina Grande/PB onde 20 raizeiros foram questionados sobre a comercialização e indicação de plantas medicinais para tratar feridas, 18 espécies vegetais foram citadas demonstrando a variedade de espécies que tem sido utilizadas para este fim ${ }^{(19)}$.

Das 48 plantas citadas, sete (Sambacaitá, Urtiga Aberta, Uchi Amarelo, Corona, Xiquexique, Sena e Pindaíba) não foram encontrados estudos que comprovem sua indicação para o uso em feridas. Esses achados indicam a necessidade de investigações científicas sobre a eficácia dessas plantas utilizadas no combate às feridas que acometem o ser humano.

Dez das 48 espécies (Catuaba, Espinheira Santa, Alecrim, Boldo, Anis Estrelado, Açafrão, Canela, Cana do Brejo, Cedro, Ameixa) não possuem atividade cicatrizante de acordo com os estudos encontrados. Apesar de existir a possibilidade destas plantas medicinais possuírem outras propriedades biológicas, a indicação destas para atividade cicatrizante reflete o limitado conhecimento científico destes comercializantes sobre os produtos que revendem e indicam para tal fim.

A casca, citada em $96,15 \%$ das entrevistas é a parte da planta mais comercializada pelos raizeiros. Isto pode estar relacionado à facilidade de uso desta parte da planta, que pode ser utilizada na decocção, infusão ou até maceração possibilitando seu uso em forma de chás, garrafadas, banhos, pós ou unguentos. Esta variedade de produtos a serem comercializados podem favorecer este destaque de venda.

A maioria dos raizeiros $(53,8 \%)$ indicam as referidas plantas medicinais para todos os tipos de feridas sejam elas internas ou externas. Esta condição demonstra a falta de conhecimento que os raizeiros demonstram sobre os efeitos toxicológicos que o uso destas espécies vegetais podem acarretar para os seus usuários.

$\mathrm{Na}$ sociedade atual existe uma grande preocupação girando em torno da conservação da natureza, assim como a procura por conhecimentos populares no uso das espécies vegetais, causando assim uma procura cada vez maior por essa terapia complementar ${ }^{(16)}$.

O retorno dos clientes, referido por $61,55 \%$ dos entrevistados, para novas compras de outras plantas medicinais, associada ou não da mesma adquirida anteriormente, é visto de forma positiva por todos os entrevistados. O fato de o cliente retornar querendo comprar outras plantas medicinais não aparenta 
suscitar nos raizeiros a impressão da planta medicinal anteriormente comercializada não ter surtido o efeito desejado. Isto pode estar relacionada ao fato da manutenção da oportunidade de venda e a possibilidade de uma nova tentativa terapêutica sugerida por eles.

Em relação ao armazenamento das plantas medicinais 81,03 \% dos raizeiros afirmaram deixar seus produtos secos ou em locais secos, o que demonstra conhecimento sobre o favorecimento da proliferação de microrganismos nos produtos comercializados por meio da umidade. Contudo, apenas $43,35 \%$ destes referiram o uso de plásticos ou embalagens para armazenamento. Isto aparenta que o conhecimento sobre a contaminação por formas espiraladas é limitado a apenas uma minoria dos entrevistados.

A inadequação higiênico-sanitária da estrutura física e das práticas de comercialização/armazenamento, são favoráveis à introdução e proliferação de microbiota indesejável nos produtos disponíveis ${ }^{(16)}$.

A contaminação de plantas medicinais por fungos e bactérias patogênicas tem sido relatada mundialmente e é reconhecida pela Organização Mundial da Saúde como um problema de saúde pública. Dentre as consequências potenciais relacionadas à presença de microbiota deteriorante e/ou patogênica nas plantas medicinais está a perda de seus princípios ativos e a promoção de infecções/intoxicações no usuário final $^{(16)}$.

Essa preocupação também reflete no tempo de validade das plantas medicinais comercializadas, pois chama a atenção que $69,3 \%$ dos raizeiros afirmaram que as plantas possuem prazo indeterminado. Porém, alguns autores colocam que as plantas medicinais não devem permanecer em estoque por períodos superiores a três meses, mesmo sob condições de armazenagem adequadas ${ }^{(16)}$.

A ação terapêutica de uma planta medicinal advém de um ou mais princípios ativos presentes entre as centenas de substancias originárias do seu metabolismo primário ou secundário, componentes do que são conhecidos como fitocomplexos ${ }^{(3)}$. Imediatamente após a colheita inicia-se a alteração química do fitocomplexo, resultado de hidrólises, exposição excessiva a luz ou ao calor, oxidação ou através do metabolismo de contaminantes microbianos ${ }^{(7)}$. Tais alterações podem resultar na diminuição ou perda da(s) atividade(s) terapêutica(s) esperada(s), toxicidade e/ou reações adversas nos usuários.

Quanto ao tempo de utilização após o preparo das plantas medicinais, 73,1 \% dos entrevistados afirmou que devem ser utilizados de imediatamente até 24 horas após o preparo. Isto mostra que a maioria dos entrevistados entende que os componentes ativos dos preparados podem perder a atividade com o passar do tempo de preparo. No entanto, esta prática não segue nenhuma padronização ou conhecimento sistematizado. É notória a ausência de protocolo para recomendações sobre preparo, armazenamento e tempo de validade e/ou utilização.

Sobre informações relativas à interação com outras plantas medicinais, 50\% negaram ser possível esse processo. Esse fato explica-se quando se fala que diante do risco potencial de interações indesejáveis entre fitoquímicos deve-se considerar o consumo dos denominados "preparos tradicionais" comuns na medicina tradicional nordestina ${ }^{(16)}$. Tais produtos são extratos de base alcoólica, aquosa ou xaropes à base de açúcar, 
nos quais estão associadas diversas plantas medicinais ${ }^{(16)}$.

Com a massificação do conceito distorcido de que "o que é natural não faz mal" e a comercialização por pessoas que não detém o conhecimento etnobotânico, existe o risco de adulteração das fórmulas com a inclusão de uma ou mais espécies vegetais não indicadas. Tais modificações podem gerar as interações, afetando a segurança e a eficácia do tratamento, resultando em risco à saúde do usuário ${ }^{(16)}$.

Cada vez mais estudos que visem esclarecer atividades e princípios ativos das plantas medicinais são necessários, tendo em vista que os padrões de consumo da população ocorrem muito mais com base na tradição popular do que nos princípios que estas espécies possuem.

\section{CONCLUSÃO}

Pouco se sabe sobre a cultura dos raizeiros comerciantes das feiras livres espalhados pelo mundo todo, porém são estudos como este que podem ampliar o conhecimento acerca do uso de plantas medicinais, bem como aqueles que buscam a comprovação científica destes.

A comercialização de plantas medicinais nas feiras livres de Maceió/Alagoas/Brasil é feita por raizeiros que indicaram 48 espécies para o tratamento de feridas, entre elas algumas das quais não foram encontradas estudos com propriedades que comprovam sua indicação para o uso em feridas, por meio da análise da literatura.

Investigações científicas que comprovem a eficácia dessas plantas utilizadas no tratamento de ferida, bem como os possíveis efeitos colaterais que essa utilização pode causar precisam ser incentivadas, pois trazem informações preciosas para uso seguro deste recurso terapêutico.

Além disto, capacitações para os raizeiros sobre práticas de comercialização de plantas medicinais seguindo padronização sobre eficácia/atividade, preparo, armazenamento, conservação, prazo de validade/consumo, entre outros, também devem ser realizadas.

\section{REFERÊNCIAS}

1. Badke MR, Budó MLD, Silva FM, Ressel LB. Plantas medicinais: o saber sustentado na prática do cotidiano popular. Esc Anna Nery [Internet]. 2011 [acesso em: 31 mar. 2016];15(1):132-9. Disponível em:

http://dx.doi.org/10.1590/S1414-81452011000100019.

2. Sampaio LA, Oliveira DR, Kerntopf MR, Brito Júnior FE, Menezes IRA. Percepção dos enfermeiros da estratégia saúde da família sobre o uso da fitoterapia. Reme Rev Min Enferm [Internet]. 2013 [acesso em: 31 mar.

2016];17(1):76-84. Disponível em: http://www.reme.org.br/artigo/detalhes/580.

3. Ministério da Saúde. Programa Nacional de Plantas Medicinais e Fitoterápicos [Internet]. Brasília: Editora do Ministério da Saúde; 2009 [acesso em: 31 mar. 2016]. Disponível em:

http://bvsms.saude.gov.br/bvs/publicacoes/programa_nacional_plantas_medicinais_fitoterapicos.pdf.

4. Pinho L, Souza PNS, Macedo Sobrinho E, Almeida AC, Martins ER. Atividade antimicrobiana de extratos hidroalcoolicos das folhas de alecrim- pimenta, aroeira, barbatimão, erva baleeira e do farelo da casca de pequi. Ciência Rural [Internet]. 2012 [acesso em: 31 mar. 2016];42(2):326-31. Disponível em: http://dx.doi.org/10.1590/S0103-84782012005000003.

5. Santos SLDX, Alves RNN, Santos SLDX, Barbosa JAA, Brasileiro TF. Plantas utilizadas como medicinais em uma comunidade rural do semi-árido da Paraíba, Nordeste do Brasil. Rev. Bras. Farm. [Internet]. 2012 [acesso em: 31 mar. 
2016];93(1):68-79. Disponível em: http://www.rbfarma.org.br/files/rbf-2012-93-1-12.pdf.

6. Silva LWF. Plantas medicinais usadas pela população do município de Sertãozinho - Paraíba: um recurso didático no ensino médio [Monografia]. Paraíba: UFPB; 2013.

7. Leão MFDM, Souza RO, Duarte JA, Souza MN, Oliveira LF, Machado MM. Análise fitoquímica da folha de Quebra Pedra (Phyllanthus niruri L.) com ênfase em compostos antioxidantes. Anais do Salão Internacional de Ensino, Pesquisa e Extensão [Internet]. 2012 [acesso em: 31 mar. 2016];4(2). Disponível em:

http://seer.unipampa.edu.br/index.php/siepe/article/view/1772.

8. Conceição GM, Ruggieri AC, Araujo MFV, Conceição TTMM, Conceição MAMM. Plantas do cerrado: comercialização, uso e indicação terapêutica fornecida pelos raizeiros e vendedores, Teresina, Piauí. Scientia Plena [Internet]. 2011 [acesso em: 31 mar. 2016];7(12):1-6. Disponível em: http://www.scientiaplena.org.br/sp/article/view/23/421. 9. Carvalho JSB, Martins JDL, Mendonça MCS, Lima LD. Uso popular das plantas medicinais na comunidade da Várzea, Garanhuns-PE. Revista de Biologia e Ciências da Terra [Internet]. 2013 [acesso em: 31 mar. 2016];13(2):58-65. Disponível em: http://joaootavio.com.br/bioterra/workspace/uploads/artigos/768-2912-1-pb-53df96b4789a6.pdf. 10. Lima RA, Magalhães AS, Santos MRA. Levantamento Etnobotânico de plantas medicinais utilizadas na cidade de Vilhena, Rondônia. Revista Pesquisa \& Criação [Internet]. 2011 [acesso em: 31 mar. 2016];10(2):165-79. Disponível em: http://www.periodicos.unir.br/index.php/propesq/article/viewFile/422/474.

11. Oliveira AF, Batista JS, Paiva ES, Silva AE, Farias YJMD, Damasceno CAR, et al. Avaliação da atividade cicatrizante do jucá (Caesalpinia férrea Mart. Ex Tul. var. ferrea) em lesões cutâneas de caprinos. Rev. bras. plantas. Med. [Internet]. 2010 [acesso em: 31 mar. 2016];12(3):302-10. Disponível em: http://dx.doi.org/10.1590/S1516-05722010000300007. 12. Rodrigues VEG, Carvalho DA. Levantamento etnobotânico de plantas medicinais no domínio do cerrado na região do Alto Rio Grande-Minas Gerais. Ciênc. agrotec. [Internet]. 2001 [acesso em: 31 mar. 2016];25(1):102-23. Disponível em: https://www.agencia.cnptia.embrapa.br/recursos/FLO_Etnob_Cerrado_MGID-0zWHItLEGY.pdf.

13. Ministério da Saúde. Relação nacional de medicamentos essenciais: RENAME 2013. 8ª ed. Brasília: Ministério da Saúde; 2014.

14. Leite IA, Marinho MGV. Levantamento etnobotânico de plantas medicinais em comunidade indígena no município de Baía da Traição-PB. Biodiversidade [Internet]. 2014 [acesso em: 31 mar. 2016];13(1):82-105. Disponível em: http://periodicoscientificos.ufmt.br/ojs/index.php/biodiversidade/article/view/1542.

15. Morais IC, Silva LDG, Ferreira HD, Paula JR, Tresvenzol LMF. Levantamento sobre plantas medicinais comercializadas em Goiânia: abordagem popular (raizeiros) e abordagem científica (levantamento bibliográfico). Revista Eletrônica de Farmácia [Internet]. 2005 [acesso em: 31 mar. 2016];2(1):13-6. Disponível em: https://revistas.ufg.br/REF/article/view/1961.

16. Rocha FAG, Araújo LSG, Lima TGD, Silva ER, Silva PA, Gundim MKM, et al. Características do comércio informal de plantas medicinais no município de Lagoa Nova/RN. HOLOS [Internet]. 2013 [acesso em: 31 mar. 2016];5(ano 29):26481. Disponível em: http://dx.doi.org/10.15628/holos.2013.1344.

17. Silva PA, Faria LA, Espinheira MJCL, Mascarenhas GDM, Silva KO. O perfil dos raizeiros e a comercialização de plantas medicinais em feiras livres do município de Vitória da Conquista, Bahia. Ex@tas Online [Internet]. 2014 [acesso em: 31 mar. 2016];5(2):8-18. Disponível em: http://www2.uesb.br/exatasonline/images/V5N2pag8-18.pdf. 18. Pinho L, Souza PNS, Sobrinho EM, Almeida AC, Martins ER. Atividade antimicrobiana de extratos hidroalcoólicos das folhas de alecrim-pimenta, aroeira, barbatimão, erva baleeira e do farelo da casca de pequi. Ciênc. Rural [Internet]. 2012 [acesso em: 31 mar. 2016];42(2):326-31. Disponível em: http://dx.doi.org/10.1590/S010384782012005000003.

19. Souza. DR. A importância do conhecimento popular sobre fitoterápicos usados para tratar feridas [monografia]. Paraíba: UEPB; 2013. 